\title{
Platelet rich plasma following hysteroscopic adhesolysis: a randomized clinical trial
}

\author{
Mortada E. Ahmed ${ }^{1 *}$, Mohamed I. Amer ${ }^{1}$, Walaa E. Ahmed ${ }^{2}$
}

${ }^{1}$ Department of Obstetrics and Gynecology, Faculty of Medicine, Ain Shams University, Cairo, Egypt.
${ }^{2}$ Department of Obstetrics and Gynecology, Faculty of Medicine, Helwan University, Cairo, Egypt

Received: 20 November 2020

Accepted: 04 January 2021

*Correspondence:

Dr. Mortada E. Ahmed,

E-mail: mortadaelsayed@yahoo.com

Copyright: $\odot$ ( the author(s), publisher and licensee Medip Academy. This is an open-access article distributed under the terms of the Creative Commons Attribution Non-Commercial License, which permits unrestricted non-commercial use, distribution, and reproduction in any medium, provided the original work is properly cited.

\section{ABSTRACT}

Background: Intrauterine adhesions (IUAs) is an uncommon condition that occurs after endometrial trauma, still it affects many women seeking fertility. Hystroscopic adhesolysis is the standard management procedure for IUAs, yet many concerns arise about the incidence of recurrence. This study evaluates the efficacy of Platelet rich plasma in decreasing adhesion recurrence following hystroscopic adhesolysis of severe intrauterine adhesions.

Methods: A prospective randomized clinical trial held in the Endoscopy Unit of Ain Shams University Hospital, Cairo, Egypt. 160 women with grade-III intrauterine adhesions, according to American Fertility Society criteria, were randomized to either receiving $5 \mathrm{ml}$ platelet rich plasma injection into the uterine wall in the most affected parts of the endometrium and lining the uterine cavity by $5 \mathrm{ml}$ platelet rich plasma gel followed by intrauterine insertion of folley's catheter balloon left for two weeks (study group), or only insertion of folley's catheter balloon for two weeks with injection of placebo solution and using placebo gel (control group). Second look office hysteroscopy was performed 3 months post-operative to assess the grade of intrauterine adhesions. The primary outcome was the incidence of recurrence of intrauterine adhesions. Secondary outcomes were the post-operative improvement of menstrual duration and flow, and pregnancy rate within 1 year post-adhesolysis.

Results: 70/81(86.4\%) patients showed grade-I adhesions, $8 / 81(9.9 \%)$ grade-II and 3/81 (3.7\%) remained grade-III in the study group compared to $42 / 78(53.8 \%)$ grade-I, $21 / 78$ (26.9\%) grade II and 15/78 (19.2\%) grade-III in the control group $(\mathrm{p}<0.001)$.

Conclusions: Platelet rich plasma shows better improvement of adhesion score, menses duration and menses amount following hystroscopic dissection of severe intrauterine adhesions.

Keywords: Asherman's syndrome, Adhesion recurrence, Hystroscopic adhesolysis, Intrauterine adhesions, Intrauterine synechia, Operative hysteroscopy, Platelet rich plasma

\section{INTRODUCTION}

Asherman's syndrome or intrauterine adhesions (IUAs) are defined as adhesions or fibrous strings between the opposing uterine walls. ${ }^{1}$ It usually results secondary to endometrial trauma as uterine curettage or surgery or intrauterine infection specially post-partum. ${ }^{2}$ Severity of adhesions varies from focal small bands up to extensive or even complete uterine occlusion. ${ }^{2}$ It might lead to partial or complete endometrial dysfunction and impaired fertility or menstrual pattern. ${ }^{3}$ It is one of the conditions that have great impact on; pregnancy and pregnancyrelated complications as abnormal placentation, miscarriage, infertility and poor implantation results in assisted reproduction techniques. ${ }^{3,4}$

Hysteroscopy is considered to be the gold-standard procedure for both diagnosis and treatment of intrauterine synechia. ${ }^{5}$ Prevention of occurrence of IUAs and its recurrence is a challenging issue in clinical practice. Several methods have been proposed for prevention of recurrence after hystroscopic adhesolysis, these include; 
cyclic hormonal therapy, insertion of IUD or intrauterine balloons, also hyaluronic acid gel and amnion graft have been studied with promising results. ${ }^{4}$ Post-operative hormonal treatment is used to restore normal endometrium and postoperative hystroscopic and ultrasound assessment is usually applied. ${ }^{6}$ The use of IUD for prevention of IUAs recurrence was one of the first attempts in this field. ${ }^{7}$ IUD was thought to help physiological endometrial regeneration keeping the uterine walls separated apart. ${ }^{8}$ The use of heart-shaped intrauterine balloon showed similar results to the use of IUD. ${ }^{9}$ Several studies showed promising results when using fresh amnion graft fitted over a folley's catheter balloon in patients with moderate IUAs, still, the results were not very promising in cases with severe IUAs. ${ }^{10-12}$

Platelet rich plasma (PRP) is an autologous blood derivative prepared by gradient density centrifugation. It is safe and effective as a promoting factor for wound healing. PRP stimulates angiogenesis and accelerates epithelial, endothelial and epidermal regeneration with an added antimicrobial effect due to its high leukocyte concentration. ${ }^{13}$ PRP has been used during in vitro fertilization for endometrial growth promotion and improvement of pregnancy outcome. ${ }^{14}$ In 2018, one study suggested promising results in reducing intra-uterine adhesion recurrence when using PRP following hystroscopic adhesolysis. ${ }^{15}$

This study evaluates the efficacy of PRP in decreasing adhesion recurrence following hystroscopic adhesolysis.

\section{METHODS}

This prospective randomized clinical study was carried out in the endoscopy unit of Ain Shams University Hospital, Cairo, Egypt, from January 2016 to January 2020. The study was approved by the institutional Ethics and Research Committee and registered on ClinicalTrials.gov Protocol Registration and Results System I.D.: NCT03881215. Informed written consent was obtained from each participant at enrollment.

Women with grade-III intrauterine adhesions according to American Fertility Society criteria, diagnosed by office hysteroscopy, were enrolled in the study.16 Women with Hemoglobin <11 g/dl, platelet count $<150,000 / \mathrm{mm}^{3}$, receiving anticoagulant therapy, having active genital tract infection or undiagnosed genital bleeding were excluded from the study.

Sample size was calculated using $G^{*}$ Power® version 3.1.9.2, setting the power at 0.8 and significance level $(\alpha)$ at 0.05 . Previous data indicated a post-hystroscopic adhesolysis resolution rate of severe intrauterine adhesions of $83.3 \%$ using PRP and intrauterine balloon; compared to $60 \%$ when using intrauterine balloon alone. ${ }^{15}$ Accordingly, a minimal sample size of 67 women in each group was calculated. 160 women were randomized, using block randomization with 1:1 ratio, to either study arm (PRP group) and control arm (Balloon only group). Participants were randomized using computer generated list.

$30 \mathrm{ml}$ venous blood was withdrawn from the participant in a tube with $1.25 \mathrm{ml}$ citrate phosphate dextrose adenine1 (CPDA-1).

This was followed by two step centrifugation; first step centrifugation used 1000 gravitational force for 5 minutes and the upper layer of the centrifuged blood (plasma) was transferred to another plain tube for the second step centrifugation using 1500 gravitational force for 15 minutes. Supernatant layer (platelet- poor) was discarded and the lower $10 \mathrm{ml}$ (platelet-rich plasma) was preserved and divided into two samples.

The first sample contained PRP in a liquid form, while the second one was transferred to gel form by adding calcium gluconate $(1 \mathrm{ml}, 10 \%)$. Bovine thrombin was not added to avoid early loss of growth factors from thrombin-mediated PRP activation. ${ }^{17}$

Following routine preoperative investigations, hysteroscopic adhesolysis was performed under general anesthesia. Cervix was dilated to $6 \mathrm{~mm}$ using Hegar's dilators. Hysteroscopy was performed using a rigid $30 \mathrm{o}$; $2.9 \mathrm{~mm}$ telescope and $5 \mathrm{~mm}$ diameter diagnostic sheath with an operative channel (Karl Storz, Tuttlingen, Germany). Adhesions were removed by sharp scissors with saline distention media or monopolar needle with glycine as a distension media through an automated hysteroscopic distension pump. Dissection of adhesions was continued till assuring visualization of the ostia.

Following hystroscopic adhesolysis, participants in study group received $5 \mathrm{ml}$ PRP injection into the uterine wall in the most affected part of the endometrium and lining the uterine cavity by $5 \mathrm{ml}$ platelet rich plasma gel followed by intrauterine insertion of folley's catheter balloon inflated with $10 \mathrm{ml}$ saline and its stem was cut and was left for two weeks, while those in control group only folley's catheter balloon was inserted for two weeks and uterine cavity was lined by placebo gel after injecting a placebo solution in most affected part of the endometrium. Sealed opaque envelopes contained the allocation of the participant were prepared and revealed to an assistant nurse not involved in the study, not to the surgeon commencing the operation.

Participants were discharged from hospital on the same day and were prescribed Azithromycin (Xithrone®, Amoun Pharmaceuticals Co., Cairo, Egypt, $500 \mathrm{mg}$ film coated tablet, once daily on empty stomach for 3 days) and Cyclo-Progynova ${ }^{\circledR}$, Mylan Products Limited, Hertfordshire, UK (2 mg estradiol valerate for 21 days and adding $0.5 \mathrm{mg}$ norgestrel in the last 10 days) for 3 months following hysteroscopy. Foley's catheter balloon was removed after 2 weeks and second-look office hysteroscopy was performed after 3 month by an 
independent operator who was blinded regarding the intervention to assess the recurrence of adhesions.

The allocation of participants was not revealed except after analysis of data, so that all researchers, participants and data analysts were blinded to the allocation of the study.

The primary outcome measure was the incidence of recurrence of severe intrauterine adhesions according to American Fertility Society's adhesion score. ${ }^{16}$

Secondary outcomes were the post-operative improvement of menstrual duration and flow, measured by number of days of menstrual flow and number of sanitary pads used during menses, also, the incidence of pregnancy within 1 year following adhesolysis.

Statistical analysis was done using Statistical Package for Social Sciences version 17 (SPSS; SPSS Inc, Chicago, Illinois).

Normality of numerical data distribution was tested using D'Agostino-Pearson test. Description of quantitative (numerical) variables was as mean \pm standard deviation (SD).

Description of qualitative (categorical) data was in the form of number of cases and percentage. Analysis of numerical variables was performed using independent student's t-test and categorical data using Chi-squared test. Significance was set at $\mathrm{P}<0.05$.

\section{RESULTS}

160 of the 213 women recruited were randomized to either the study arm (82 participants) or the control arm (78 participants) (Figure 1).

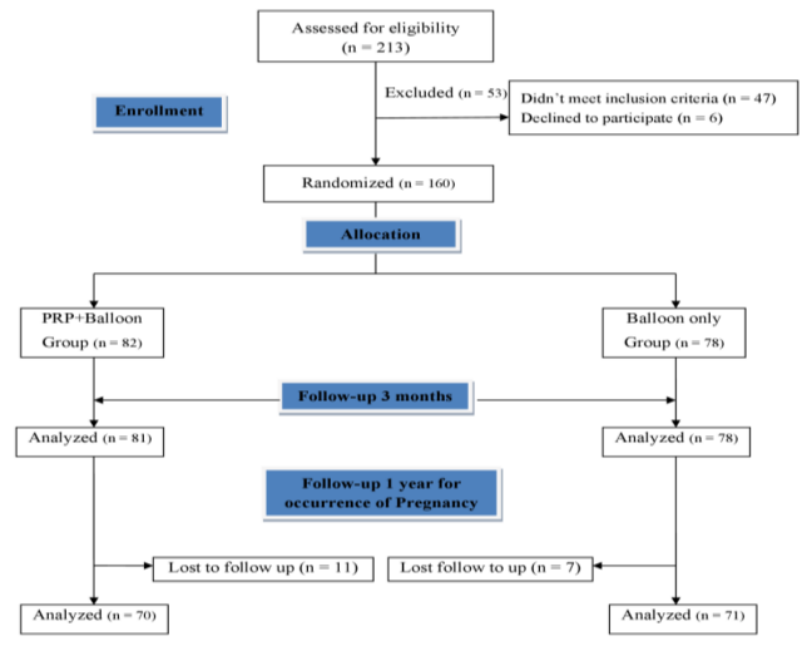

Figure 1: Flow chart of the study.
The mean age was $30.6 \pm 4.0$ years in the study arm and $31.5 \pm 3.7$ years in the control arm, and mean body mass index (BMI) was $23.6 \pm 2.5 \mathrm{~kg} / \mathrm{m}^{2}$ and $24.2 \pm 2.4 \mathrm{~kg} / \mathrm{m}^{2}$, respectively.

Second-look hysteroscopy showed better results regarding reduced recurrence of severe adhesions in the PRP group with highly significant difference when compared to the balloon only group (Table 1), yet, this improvement was not very evident in patients with recurrent IUAs in either of the two groups (Table 2).

Table 1: Adhesion grades among the studied groups.

\begin{tabular}{|c|c|c|c|c|}
\hline Items & Grade & $\begin{array}{l}\text { PRP } \\
\text { group }\end{array}$ & $\begin{array}{l}\text { Balloon } \\
\text { group }\end{array}$ & $\begin{array}{l}\mathbf{P} \\
\text { value }\end{array}$ \\
\hline $\begin{array}{l}\text { Before } \\
\text { Adhesolysis }\end{array}$ & $\begin{array}{l}\text { Grade- } \\
\text { III }\end{array}$ & $\begin{array}{l}82 \\
(100.0 \%)\end{array}$ & $\begin{array}{l}78 \\
(100.0 \%)\end{array}$ & -- \\
\hline \multirow{3}{*}{$\begin{array}{l}\text { After } \\
\text { Adhesolysis }\end{array}$} & Grade-I & $70(86.4$ & $\begin{array}{l}42 \\
(53.8 \%)\end{array}$ & \multirow{3}{*}{$\begin{array}{l}< \\
0.000 \\
1\end{array}$} \\
\hline & Grade-II & $8(9.9 \%)$ & $\begin{array}{l}21 \\
(26.9 \%)\end{array}$ & \\
\hline & $\begin{array}{l}\text { Grade- } \\
\text { III }\end{array}$ & $3(3.7 \%)$ & $\begin{array}{l}15 \\
(19.2 \%)\end{array}$ & \\
\hline \multicolumn{5}{|c|}{ Value of PRP over balloon in getting grade-I } \\
\hline \multicolumn{2}{|l|}{ Items } & Value & \multicolumn{2}{|l|}{$95 \% \mathrm{CI}$} \\
\hline \multicolumn{2}{|c|}{ Rate in PRP group } & $86.4 \%$ & \multicolumn{2}{|c|}{$67.4 \%-101 \%$} \\
\hline \multicolumn{2}{|c|}{ Rate in baloon group } & $53.8 \%$ & \multicolumn{2}{|c|}{$38.8 \%-72.8 \%$} \\
\hline \multicolumn{2}{|c|}{ Relative Rate } & 0.294 & \multicolumn{2}{|c|}{$0.162-0.536$} \\
\hline \multicolumn{2}{|c|}{$\begin{array}{l}\text { Number needed to } \\
\text { treat }\end{array}$} & 3.07 & \multicolumn{2}{|c|}{$2.182-5.176$} \\
\hline
\end{tabular}

Table 2: Adhesion grades in patients with recurrent intra-uterine adhesions.

\begin{tabular}{|c|c|c|c|c|}
\hline Items & Grade & $\begin{array}{l}\text { PRP } \\
\text { group }\end{array}$ & $\begin{array}{l}\text { Balloon } \\
\text { group }\end{array}$ & $\begin{array}{l}\mathbf{P} \\
\text { value }\end{array}$ \\
\hline $\begin{array}{l}\text { Before } \\
\text { Adhesolysis }\end{array}$ & $\begin{array}{l}\text { Grade- } \\
\text { III }\end{array}$ & $\begin{array}{l}11 \\
(100.0 \%)\end{array}$ & $\begin{array}{l}10 \\
(100.0 \%)\end{array}$ & -- \\
\hline \multirow{3}{*}{$\begin{array}{l}\text { After } \\
\text { Adhesolysis }\end{array}$} & Grade-I & $\begin{array}{l}2 \\
(18.2 \%)\end{array}$ & $1(10 \%)$ & \multirow{3}{*}{0.318} \\
\hline & $\begin{array}{l}\text { Grade- } \\
\text { II }\end{array}$ & $\begin{array}{l}6 \\
(54.5 \%)\end{array}$ & $3(30 \%)$ & \\
\hline & $\begin{array}{l}\text { Grade- } \\
\text { III }\end{array}$ & $\begin{array}{l}3 \\
(27.3 \%)\end{array}$ & $6(60 \%)$ & \\
\hline
\end{tabular}

When compared to preoperative menstrual duration and flow, both parameters were markedly improved in both arms, and improvement was more significantly evident in the PRP group (Table 3 and 4).

When following up the occurrence of pregnancy within 1 year following adhesolysis, PRP group showed clinically higher incidence of pregnancy but was not statistically significant when compared to the Balloon group (Table 5). 
Table 3: Menses duration (days) among the studied groups.

\begin{tabular}{|c|c|c|c|c|c|}
\hline Time & Measure & $\begin{array}{l}\text { PRP group } \\
(n=81)\end{array}$ & $\begin{array}{l}\text { Balloon group } \\
(n=78)\end{array}$ & $\mathbf{P}$ & $95 \% \mathrm{CI}$ \\
\hline \multirow{2}{*}{$\begin{array}{l}\text { Normal } \\
\text { (Pre-adhesions) }\end{array}$} & Mean \pm SD & $3.73 \pm 0.96$ & $3.81 \pm 0.6$ & \multirow{2}{*}{0.5313} & \multirow{2}{*}{-0.172 to 0.332} \\
\hline & Range & $2.0-6.0$ & $3.0-5.0$ & & \\
\hline \multirow{2}{*}{ Before adhesolysis } & Mean \pm SD & $1.43 \pm 1.5$ & $1.28 \pm 1.18$ & \multirow{2}{*}{0.4855} & \multirow{2}{*}{-0.574 to 0.274} \\
\hline & Range & $0.0-5.0$ & $0.0-3.0$ & & \\
\hline \multirow{2}{*}{ After adhesolysis } & Mean \pm SD & $3.1 \pm 1.06$ & $1.87 \pm 1.05$ & \multirow{2}{*}{$\begin{array}{l}< \\
0.0001\end{array}$} & \multirow{2}{*}{-1.561 to -0.899} \\
\hline & Range & $0.0-5.0$ & $0.0-4.0$ & & \\
\hline \multirow{4}{*}{$\begin{array}{l}\text { After adhesolysis - Before } \\
\text { adhesiolysis }\end{array}$} & Mean \pm SD & $1.68 \pm 1.45$ & $0.59 \pm 0.69$ & \multirow{4}{*}{$\begin{array}{l}< \\
0.0001\end{array}$} & \multirow{4}{*}{-1.448 to -0.732} \\
\hline & Range & $0.0-4.0$ & $0.0-2.0$ & & \\
\hline & $\mathrm{P}$ & $<0.0001$ & 0.0012 & & \\
\hline & $95 \% \mathrm{CI}$ & 1.267 to 2.073 & 0.237 to 0.943 & & \\
\hline
\end{tabular}

Table 4: Menses flow (number of pads) among the studied groups.

\begin{tabular}{|c|c|c|c|c|c|}
\hline Time & Measure & $\begin{array}{l}\text { PRP group } \\
(\mathbf{n}=\mathbf{8 1})\end{array}$ & $\begin{array}{l}\text { Balloon group } \\
(n=78)\end{array}$ & $\mathbf{P}$ & $95 \% \mathrm{CI}$ \\
\hline \multirow{2}{*}{$\begin{array}{l}\text { Normal } \\
\text { (Pre-adhesions) }\end{array}$} & Mean \pm SD & $9.79 \pm 4.84$ & $10.56 \pm 3.83$ & \multirow{2}{*}{0.2688} & \multirow{2}{*}{-0.601 to 2.141} \\
\hline & Range & $4.0-24.0$ & $6.0-20.0$ & & \\
\hline \multirow{2}{*}{ Before adhesolysis } & Mean \pm SD & $1.11 \pm 1.04$ & $0.96 \pm 0.97$ & \multirow{2}{*}{0.3488} & \multirow{2}{*}{-0.465 to 0.165} \\
\hline & Range & $0.0-3.0$ & $0.0-3.0$ & & \\
\hline \multirow{2}{*}{ After adhesolysis } & Mean \pm SD & $6.01 \pm 3.63$ & $2.81 \pm 2.13$ & \multirow{2}{*}{$\begin{array}{l}< \\
0.0001\end{array}$} & \multirow{2}{*}{-4.137 to -2.263} \\
\hline & Range & $1.0-15.0$ & $0.0-8.0$ & & \\
\hline \multirow{4}{*}{$\begin{array}{l}\text { After adhesolysis - Before } \\
\text { adhesiolysis }\end{array}$} & Mean \pm SD & $4.9 \pm 3.32$ & $1.85 \pm 1.46$ & \multirow{4}{*}{$\begin{array}{l}< \\
0.0001\end{array}$} & \multirow{4}{*}{-3.859 to -2.241} \\
\hline & Range & $0.0-13.0$ & $0.0-6.0$ & & \\
\hline & $\mathrm{P}$ & $<0.0001$ & 0.0012 & & \\
\hline & $95 \% \mathrm{CI}$ & 4.071 to 5.729 & 1.326 to 2.374 & & \\
\hline
\end{tabular}

Table 5: Incidence of pregnancy occurrence among groups.

\begin{tabular}{|lll|}
\hline Items & PRP group $(\mathbf{n}=\mathbf{7 0})$ & Balloon group $(\mathbf{n}=71)$ \\
\hline Pregnancy & $18(25.7 \%)$ & $10(14.1 \%)$ \\
\hline No Pregnancy & $52(74.3 \%)$ & $61(85.1 \%)$ \\
\hline & $\begin{array}{l}\text { PRP }(\text { ICSI) } \\
(\mathbf{n}=\mathbf{4 9})\end{array}$ & $\begin{array}{l}\text { Balloon (ICSI) } \\
(\mathbf{n}=\mathbf{4 5})\end{array}$ \\
\hline Pregnancy & $14(28.6 \%)$ & $7(15.6 \%)$ \\
\hline No Pregnancy & $35(71.4 \%)$ & $38(84.4 \%)$ \\
\hline & $\begin{array}{l}\text { PRP (spontaneous) } \\
(\mathbf{n = 2 1})\end{array}$ & $\begin{array}{l}\text { Balloon (spontaneous) } \\
(\mathbf{n}=\mathbf{2 6})\end{array}$ \\
\hline Pregnancy & $4(19 \%)$ & $3(11.5 \%)$ \\
\hline No Pregnancy & $17(81 \%)$ & $23(88.5 \%)$ \\
\hline
\end{tabular}

\section{DISCUSSION}

IUAs is one of the conditions that has great impact on; pregnancy and pregnancy-related complications as abnormal placentation, miscarriage, infertility and poor implantation results in assisted reproduction techniques. ${ }^{3,}$ ${ }^{4}$ Prevention of occurrence of IUAs and its recurrence is a challenging issue in clinical practice. Several methods have been proposed for prevention of recurrence after hystroscopic adhesolysis, these include; cyclic hormonal therapy, insertion of IUD or intrauterine balloons, also hyaluronic acid gel and amnion graft have been studied with promising results. ${ }^{4}$

The use of IUD for prevention of IUAs recurrence was one of the first attempts in this field. ${ }^{6}$ IUD was thought to help physiological endometrial regeneration keeping the uterine walls separated apart. ${ }^{7}$ The use of heart-shaped intrauterine balloon showed similar results to the use of IUD. ${ }^{8}$ Several studies showed promising results when using fresh amnion graft fitted over a folley's catheter balloon in patients with moderate IUAs, ${ }^{9-11}$ still in 
contrast to this study, the results were not very promising in cases with severe IUAs, also PRP being an autologous product carries less incidence of infection and complications and has the advantage of easier preparation process. The use of intrauterine balloon stent showed promising results in terms of pregnancy rate $(61.6 \%)$ and spontaneous miscarriage rate $(15.6 \%)$; yet, no data were reported about IUAs recurrence. ${ }^{18}$ Another cohort retrospective study, when compared intrauterine balloon stent to IUD and hyaluronic acid, found significant reduction in IUAs recurrence in the stent group. ${ }^{19} \mathrm{~A}$ single study proposed combined regenerated cellulose adhesion barrier and IUD to be an alternative approach to reduce adhesion recurrence but still these results need to be further verified. ${ }^{20}$

PRP is an autologous blood product prepared using gradient density centrifugation. Autologous PRP proved to be a safe and effective promoter for wound healing and tissue regeneration, even endometrial growth and regeneration. ${ }^{13,14}$ It has a haemostatic and tissue sealing property and works as a fibrin tissue adhesive with better healing power through its growth factors content which is released within 10 minutes. ${ }^{13}$

To our knowledge, only two previous studies addressed the use of PRP following hystroscopic adhesolysis combined with intrauterine balloon and showed promising results when compared to the use of balloon alone regarding prevention of severe adhesion recurrence. ${ }^{15}$ This study did not follow the impact of this technique on future fertility and pregnancy outcomes whether spontaneous or with assisted reproduction technique. On the contrary, the other study didn't find any significant difference regarding menstrual pattern, duration of menstrual bleeding, and IUAs stage. ${ }^{21}$ This study used 1-mL PRP injected into the uterine cavity two days following adhesolysis and after removal of intrauterine balloon.

The primary strength of this study is being prospective and randomized, also blinding of the second look operator decreased the bias of the results. Still, several limitations were found in this study, the multiple surgeons involved in the study didn't allow unification of surgical technique, although we tried to overcome this obstacle by ensuring visualization of tubal ostia during adhesolysis in all cases in order to be included in the study. The follow up of future pregnancy was not unified for a certain time limit for all participants, also not adopting a single reproductive technique, ICSI for example, at a unified postoperative time interval which might have decreased the bias in the reproductive outcome data. The not very promising results in cases with recurrent IUAs raises the question of whether multiple injections instead of single injection in these cases would have showed better results, still, this should be considered in future studies.
This study shows promising results for PRP in prevention of IUAs recurrence and improving menstrual flow. Autologous PRP proved to be a safe and effective promoter for wound healing and tissue regeneration, ${ }^{13}$ even endometrial growth and regeneration. ${ }^{14}$ It has a haemostatic and tissue sealing property and works as a fibrin tissue adhesive with better healing power through its growth factors content which is released within 10 minutes. ${ }^{13}$

\section{CONCLUSION}

The use of PRP with intrauterine balloon shows better improvement of adhesion score, menses duration and menses amount following hystroscopic dissection of severe intrauterine adhesions.

\section{ACKNOWLEDGMENTS}

Ain Shams University.

Funding: No funding sources

Conflict of interest: None declared

Ethical approval: The study was approved by the Ain Shams University, Faculty of Medicine, Research Ethics Committee

\section{REFERENCES}

1. Nappi C, Di Spiezio Sardo A, Greco E, Guida M, Bettocchi S, Bifulco G. Prevention of adhesions in gynaecological endoscopy. Hum Reprod Update. 2007;13(4):379-94.

2. Khan Z, Goldberg JM. Hysteroscopic Management of Asherman's Syndrome. J Minim Invasive Gynecol. 2018;25(2):218-28.

3. Yu D, Wong YM, Cheong Y, Xia E, Li TC. Asherman syndrome-one century later. Fertil Steril. 2008;89(4):759-79.

4. Deans R, Abbott J. Review of intrauterine adhesions. J Minim Invasive Gynecol. 2010;17(5):555-69.

5. Sahu L, Tempe A, Gupta S. Hysteroscopic evaluation in infertile patients: a prospective study. Int J Reprod Contracept Obstet Gynecol. 2012;1(1):37-41.

6. Shokeir TA, Fawzy M, Tatongy M. The nature of intrauterine adhesions following reproductive hysteroscopic surgery as determined by early and late follow-up hysteroscopy: clinical implications. Arch Gynecol Obstet. 2008;277(5):423-7.

7. Ventolini G, Zhang M, Gruber J. Hysteroscopy in the evaluation of patients with recurrent pregnancy loss: a cohort study in a primary care population. Surg Endosc. 2004;18(12):1782-4.

8. Lin XN, Zhou F, Wei ML, Yang Y, Li Y, Li TC, et al. Randomized, Controlled Trial Comparing the Efficacy of Intrauterine Balloon and Intrauterine Contraceptive Device in the Prevention of Adhesion Reformation After Hysteroscopic Adhesiolysis. Fertil Steril. 2015;104(1):235-40. 
9. Amer MI, Abd-El-Maeboud KH. Amnion graft following hysteroscopic lysis of intra uterine adhesions. J Obstet Gynecol Res. 2006;32(6):559-66.

10. Amer MI, Abd-El-Maeboud KH, Abdelfatah I, Salama FA, Abdallah AS. Human amnion as a temporary biologic barrier after hysteroscopic lysis of severe intrauterine adhesions: pilot study. J Minim Invasive Gynecol. 2010;17(5):605-11.

11. Peng X, Li T, Zhao Y, Guo Y, Xia E. Safety and Efficacy of Amnion Graft in Preventing Reformation of Intrauterine Adhesions. J Minim Invasive Gynecol. 2017;24(7):1204-10.

12. Conforti A, Alviggi C, Mollo A, De Placido G, Magos A. The management of Asherman syndrome: a review of literature. Reprod Biol Endocrinol. 2013; $11: 118$

13. Smith RG, Gassmann CJ, Campbell MS. Plateletrich plasma: properties and clinical applications. J Lancaster Gen Hosp. 2007;2(2):73-8.

14. Chang Y, Li J, Chen Y, Wei L, Yang X, Shi Y, et al. Autologous platelet-rich plasma promotes endometrial growth and improves pregnancy outcome during in vitro fertilization. Int J Clin Exp Med. 2015;8(1):1286-90.

15. Amer M, Ahmed M, Kamal R, Torky A. The value of using platelet rich plasma after hystroscopic analysis of severe intrauterine adhesions (A randomized controlled trial). The Egyptian Journal of Hospital Medic. 2018;71(4):2869-74.

16. American Fertility Society. The American Fertility Society classifications of adnexal adhesions, distal tubal occlusion, tubal occlusion secondary to tubal ligation, tubal pregnancies, müllerian anomalies and intrauterine adhesions. Fertil Steril. 1988;49(6):944-55.

17. Jo CH, Roh YH, Kim JE, Shin S, Yoon KS. Optimizing platelet-rich plasma gel formation by varying time and gravitational forces during centrifugation. J Oral Implantol. 2013;39(5):525-32.

18. March CM. Management of Asherman's syndrome. Reprod Biomed Online. 2011;23(1):63-76.

19. Lin X, Wei M, Li TC, Huang Q, Huang D, Zhou F, et al. A comparison of intrauterine balloon, intrauterine contraceptive device and hyaluronic acid gel in the prevention of adhesion reformation following hysteroscopic surgery for Asherman syndrome: a cohort study. Eur J Obstet Gynecol Reprod Biol. 2013;170(2):512-6.

20. Cai H, Qiao L, Song K, He Y. Oxidized, Regenerated Cellulose Adhesion Barrier Plus Intrauterine Device Prevents Recurrence After Adhesiolysis for Moderate to Severe Intrauterine Adhesions. J Minim Invasive Gynecol. 2017;24(1):80-8.

21. Javaheri A, Kianfar K, Pourmasumi S, Eftekhar M. Platelet-rich plasma in the management of Asherman's syndrome: An RCT. Int J Reprod Biomed. 2020;18(2):113-20.

Cite this article as: Ahmed ME, Amer MI, Ahmed WE. Platelet rich plasma following hysteroscopic adhesolysis: a randomized clinical trial. Int J Reprod Contracept Obstet Gynecol 2021;10:433-8. 